Revue d'histoire de l'Amérique française

DEVVUE D.HISTOIRE DE L'AMÉRIQUE FRANÇAISE

\title{
ROBY, Yves, Histoire d'un rêve brisé ? Les Canadiens français aux États-Unis (Sillery, Septentrion, 2007), 148 p.
}

\section{Sylvie Beaudreau}

Volume 61, numéro 3-4, hiver-printemps 2008

Dossier Québec

URI : https://id.erudit.org/iderudit/019154ar

DOI : https://doi.org/10.7202/019154ar

Aller au sommaire du numéro

Éditeur(s)

Institut d'histoire de l'Amérique française

ISSN

0035-2357 (imprimé)

1492-1383 (numérique)

Découvrir la revue

Citer ce compte rendu

Beaudreau, S. (2008). Compte rendu de [ROBY, Yves, Histoire d'un rêve brisé ? Les Canadiens français aux États-Unis (Sillery, Septentrion, 2007), 148 p.] Revue d'histoire de l'Amérique française, 61(3-4), 593-596.

https://doi.org/10.7202/019154ar d'utilisation que vous pouvez consulter en ligne. 
Pagé signe une argumentation convaincante en faveur de la centralité de la radio dans la formation de la culture et de la société québécoise.

ANNE F. MacLENNAN

Département de communication

Université York

Révision: Jean-Louis Trudel

ROBY,Yves, Histoire d'un rêve brisé? Les Canadiens français aux États-Unis (Sillery, Septentrion, 2007), $148 p$.

Ce livre pourrait porter le titre Pour en finir avec les Franco-Américains. La plus récente publication d'Yves Roby consiste en six articles qui ont déjà été publiés dans d'autres collections. En les rassemblant dans un volume, Roby donne l'impression que ces textes constituent une dernière réflexion sur le sujet auquel il a dédié sa carrière plus que n'importe quel autre historien québécois. On retrouve ici le maître chercheur et l'artiste qui s'expriment dans un langage évocateur. L'auteur trace l'histoire de la croissance et du déclin ultime de la communauté d'émigrants canadiensfrançais qu’on a nommée Franco-Américains. On se demanderait peutêtre pourquoi et comment cette communauté déjà si vivante $\mathrm{a}$, à toutes fins utiles, totalement disparu du radar culturel des États-Unis. Les Américains d'origine irlandaise ont développé, depuis leur arrivée sur la terre d'exil, un sens assez distinct de leur identité irlando-américaine. Il en va ainsi pour les citoyens d'origine italienne, que cela soit par la nourriture, les fêtes de rues ou par la culture de masse, comme le cinglant succès de la série télévisée Les Sopranos. Les Italiens-Américains ont maintenu une sorte d'identité ethnique qui symbolise, tant bien que mal, la culture de leurs ancêtres de l'Italie. En même temps, ils contribuent à la culture populaire des États-Unis. Ils forment une communauté reconnaissable. On pourrait se demander pourquoi les Canadiens français, eux, n'ont pu sauvegarder aucun sens de leur identité, et semblent avoir été oblitérés de la scène culturelle américaine. Pourquoi se sont-ils complètement fondus dans le melting pot américain au point de disparaittre? Ce dernier livre de Yves Roby fournit des réponses à ces questions.

Si l'on prend une vue d'ensemble, ce qui ressort de ces essais, c'est le thème persistant du conflit entre les soi-disant «élites» clérico-nationales, qui ont lutté pour la survivance culturelle de cette communauté d'individus venant du Canada, et la «masse» de ces émigrants, qui étaient poussés à 
prendre des décisions importantes, non pas par considérations culturelles ou idéologiques, mais pour des raisons d'ordre pratique. Dans le premier chapitre, intitulé «Partir pour les États», Roby nous fournit les données nécessaires pour comprendre comment les Canadiens français fuyaient la pauvreté et que les vagues de départs étaient hautement reliées aux fluctuations cycliques de l'économie nord-américaine. Il établit que cette migration, au départ temporaire, devient avec les années permanente, que c'est par "grappes familiales» que les départs se font, et que ce processus de migration en chaîne amène des familles étendues, et parfois des paroisses entières, à favoriser certains centres industriels américains. Chose intéressante, il note qu'en raison des fameux «encombrement[s] des professions libérales», ce mouvement migratoire comptait aussi des individus de classe moyenne, un groupe d'émigrants qu'il caractérise de "chômeurs instruits ». Ainsi, le Canada français a exporté non seulement des individus d'origine humble qui allaient travailler comme manœuvres dans les usines de textiles du nord-est, mais aussi un groupe instruit et lettré capable de former une petite bourgeoisie, c'est-à-dire une élite.

Le deuxième chapitre porte un regard sur la centralité de la paroisse nationale sur la survivance culturelle des Franco-Américains. Roby établit que pour ce groupe d'expatriés et pour leurs descendants immédiats, c'est la paroisse qui constituait une sorte de "petite patrie", un havre du catholicisme franco-canadien dans un pays majoritairement protestant et anglophone. C'est par la paroisse nationale que l'élite cléricale de la Nouvelle-Angleterre a pu assurer la survie de la langue française et du catholicisme pratiqué dans le pays d'origine. C'est par l'entremise des prêtres, des religieuses, des églises et des institutions paroissiales qu'un réseau, une sorte de patrie invisible, s'est constitué à travers les États-Unis.

C’est l'Église qui, après avoir condamné l'émigration comme un acte de trahison nationale, en est venue ultimement à changer de ton et à embrasser ce mouvement comme faisant preuve de la volonté de Dieu de répandre la vraie foi, celle des catholiques romains, aux États-Unis. Les émigrés n'étaient pas des êtres minables, de simples manœuvres ou des prolétaires exploités par les capitalistes américains. Ils portaient le flambeau catholique dans un pays de protestants égarés de la vraie Église du Christ. Dans cette vision des choses, la formule pour la survivance canadienne-française, «la langue, gardienne de la foi», s'appliquait tout autant aux communautés vivant hors Québec. Ici Roby trace la longue évolution de la paroisse qui, au début, était unilingue française, mais qui devient lentement bilingue vers le tournant $\mathrm{du} \mathrm{xx}^{\mathrm{e}}$ siècle, et de plus en plus uni- 
lingue anglaise dans les années 1930 . Roby semble dire que cette formule de survivance culturelle, qui liait la langue à la religion, n’a pas survécu au processus d'anglicisation inévitable de ce groupe d'émigrants. Après une ou deux générations, quand la langue a disparu, il n’y restait que la foi, et les paroisses nationales ont fermé, ou sont devenues "territoriales » (c'est-à-dire non nationales).

Dans un chapitre sur la Société du bien parler français, Roby nous indique pourquoi et comment les élites des deux côtés de la frontière se sont tant souciées de la qualité de la langue, car sans la langue, aucune survivance culturelle n'était possible. La encore, les élites protestaient et haranguaient, mais la masse s'anglicisait à pas de géant. Ensuite, Roby consacre tout un chapitre à une de ces âmes d'élite, le père Thomas-Marie Landry, et montre comment cet être vaillant s'est battu avec acharnement pour la survivance culturelle de son peuple. On ne peut que sourire lorsqu'on lit que quand on lui demande, en 1972, où s'en va la FrancoAméricanie, il réplique, «Chez le diable».

C’est l'élite franco-américaine qui fut responsable du développement d'un sens d'identité, et Roby démontre le rôle fondamental que l'histoire a joué dans leur vision romantique du fait français en Amérique. Ce dernier chapitre est peut-être le plus faible de la collection, car Roby y reprend des idées de ses publications précédentes, et il aurait pu pousser son analyse plus loin, étant donné que cette élite fut responsable, ultimement, de la disparition de l'identité franco-américaine. Pour renverser le sens d'une expression de Roby, on pourrait dire que «La façon dont une société imagine son passé influe à son tour sur sa vision du futur. » Se peut-il que cette vision passéiste, empreinte de nostalgie, de religion et d'idéalisme, n'a pas pu survivre au modernisme des années d'après-guerre, et que lorsqu'elle s'est écroulée, il n’y avait rien pour la remplacer? On aurait aimé que Roby nous dise quelque chose sur ce sujet.

Enfin, le titre du livre est peut-être indicateur de la nature ambivalente de la communauté franco-américaine. S'il s'agit de l'histoire d'un rêve brisé, de quel rêve s'agit-il ? S’il est question du rêve des élites, celui selon lequel ce groupe d'immigrés allait refranciser la république américaine et la reconvertir au catholicisme romain, on ne peut que constater que ce rêve fut «brisé». Mais pour la «masse», pour les centaines de milliers de Canadiens français qui ont cherché la prospérité, l'aventure ou le dépaysement, il se peut fort bien que leurs rêves se soient bel et bien réalisés. Pour le lecteur québécois, ce livre est un sombre rappel du fait que la survivance d'une culture est basée sur la vitalité linguistique. 
En guise de conclusion, il me semble que ces essais susciteraient plus d'intérêt aux États-Unis où certains membres de la communauté francoaméricaine se demandent, à la veille de commémorer la venue, il y a quatre cents ans, de Champlain dans la vallée qui porte aujourd'hui son nom, ce qu'est devenue la culture franco-américaine. Malheureusement, comme ils ont perdu leur langue, ils ne peuvent pas lire le bilan que Roby trace de leur groupe dans cet admirable volume.

SYLVIE BEAUDREAU

Département d'histoire State University of New York at Plattsburgh

VAN DIE, Marguerite, Religion, Family, and Community in Victorian Canada:The Colbys of Carrollcroft (Montreal, McGill-Queen's University Press, 2006), xx-282 p.

Ce livre de Marguerite Van Die est une étude intensive de la famille Colby de Stanstead en Estrie. En exploitant une vaste correspondance intergénérationnelle, Van Die se concentre sur un thème en particulier, soit celui de la religion, vue comme une «expérience vécue» au sein de la famille. Elle cherche à donner une nouvelle interprétation à l'histoire religieuse en affirmant que la transition majeure vers l'évangélisme libéral, manifeste à la fin du $\mathrm{XIX}^{\mathrm{e}}$ siècle, s'est produite à l'intérieur de la sphère religieuse domestique et non dans celle de l'Église institutionnelle. Il est aussi à noter que Van Die croie que cette importante mutation religieuse a une connotation sociale, dans la mesure où elle reflète les aspirations de la classe moyenne émergente. Les apports historiographiques que le livre prétend fournir couvrent un large spectre. Or, bien que l'auteure dresse un portrait, assez bien écrit, de la vie familiale de la classe moyenne, d'un point de vue méthodologique le choix d'appuyer son étude sur l'histoire d'une seule famille (même une famille qui a produit une riche correspondance à travers trois générations) révèle à la fois des forces et des faiblesses. En basant son étude de cas sur la famille Colby, Van Die peut facilement illustrer la manière dont les changements socio-économiques ont modifié la vie familiale et religieuse à la fin du XIx ${ }^{\mathrm{e}}$ siècle et au début $\mathrm{du} \mathrm{xx}^{\mathrm{e}}$, bien qu'il faille reconnaître que l'intérêt principal de l'auteure reste la vie conjugale de Charles et Hattie Colby au milieu de l'époque victorienne.

Il est clair que l'intérêt de Van Die pour cette famille découle de sa vaste correspondance, mais l'auteure aurait dû expliquer aux lecteurs en quoi 